\section{Surveillance Program}

\section{September 2019}

\section{What are our priorities?}

The National Institute for Occupational Safety and Health (NIOSH) Surveillance Program works with partners in industry, labor, trade associations, professional organizations, government agencies, and academia. The program focuses on:

- Expanding awareness, knowledge, and use of occupational safety and health (OSH) surveillance data

- Building capacity for state-based OSH surveillance

- Integrating OSH variables into general health surveillance systems

- Supporting industry sector and health and safety cross-sector surveillance needs and addressing crosscutting surveillance issues

\section{What do we do?}

- Increase awareness and promote use of $\mathrm{OSH}$ surveillance data tools and resources.

- Share OSH documents produced by states through the State-based Occupational Health Clearinghouse.

- Increase the number of states that include industry and occupation questions in the CDC's Behavioral Risk Factor Surveillance System (BRFSS).

- Increase states' capacity to conduct case-based surveillance of priority occupational injuries and illnesses.

- Sponsor OSH questions in national populationbased surveys.

- Promote inclusion of OSH variables into standards for electronic health records and CDC surveillance systems.

- Identify opportunities to use novel sources of surveillance data, such as audiometric data and workers' compensation data.

- Provide web-based tools and resources, such as the Worker Health Charts (WHC) data visualization tool and the NIOSH Industry and Occupational Computerized Coding System (NIOCCS).

\section{What have we accomplished?}

- Completed data collection for the Mining Industry and Workforce Survey in metal, nonmetal, stone, and sand and gravel mining sectors.

- Added 14 health/behavior outcomes from 20132015 BRFSS surveys to WHC.

- Published an article on health insurance coverage and Tdap (tetanus, diphtheria, pertussis) vaccination by industry and occupation (I\&O) using BRFSS data.

- Published an article on drug overdose deaths by occupation using National Occupational Mortality Surveillance (NOMS) data.

\section{What's next?}

- Release an interactive version of NIOSH Mine and Mine Worker Charts.

- Complete data collection for the Mining Industry and Workforce Survey for the coal industry.

- Implement the redesigned Commercial Fishing Incident Database to improve collection of nonfatal injuries in routine surveillance activities for the US fishing industry.

- Publish papers describing health indicators among low-wage, direct-support healthcare workers and low back pain among workers.

- Perform 10-state pilot test of methods to update the NOMS system to improve efficiency and timeliness of $I \& O$ coding of death certificates.

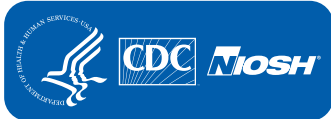

Centers for Disease Contro
- Completed reports on the burden of all occupational diseases, occupational respiratory diseases, occupational robot-related injuries, and costs of workers' compensation for hearing loss in the US.

- Prepared technical guidance and standards with standard development organizations for industry, occupation, and other occupational data in electronic health records.

- Developed silicosis-reporting specifications, which were released by the Council of State and Territorial Epidemiologists for use with their Reportable Conditions Knowledge Management System.

- Provide extensive input for three electronic health records data sharing standards, which will be published by Health Level 7 (HL-7) International ${ }^{\circledR}$ as Standards for Trial Use.

- Release update of NIOCCS using machinelearning techniques to improve autocoding rates and accuracy of assigned census industry and occupation codes.

- Develop an adult and childhood blood lead Message Mapping Guide in collaboration with other parts of CDC. The blood lead Message Mapping Guide uses HL-7 standards to specify lead exposure information sent to CDC.

Mention of any company or product does not constitute endorsement by the National Institute for Occupational Safety and Health, Centers for Disease Control and Prevention.
The Surveillance Program improves worker safety and health by identifying and tracking workplace injuries, illnesses, hazards, deaths, and exposures in the United States. This snapshot shows recent accomplishments and upcoming work.

\section{Number of NIOSH surveillance systems with} publicly searchable data

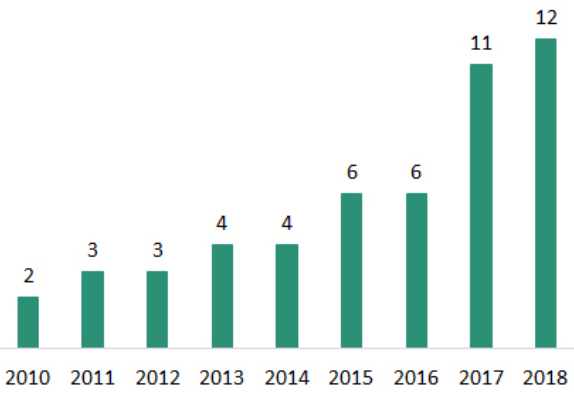

Source: NIOSH Program Records

\section{Cumulative number of records submitted* to} NIOCCS

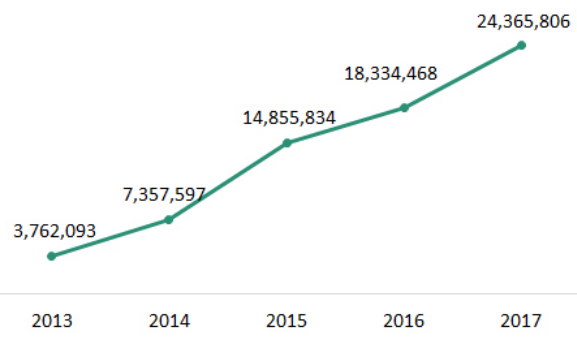

*Includes both internal and external user submissions, crosswalks, and industry and occupation coding.

Source: NIOSH Program Records

Spotlight: Worker Health Charts data visualization tool

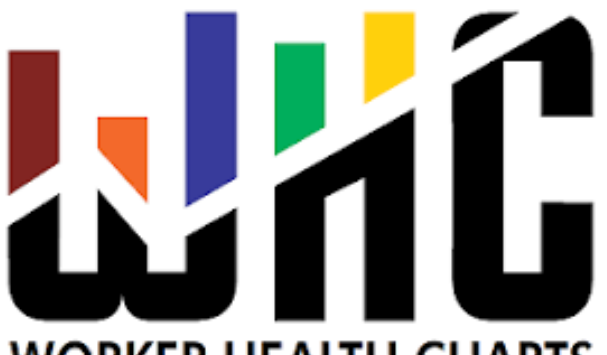

WORKER HEALTH CHARTS

To learn more, visit

www.cdc.gov/niosh/topics/surveillance

https://doi.org/10.26616/NIOSHPUB2019160 DHHS (NIOSH) Publication No. 2019-160 